\title{
Conceptual Design Report for the NGNP Tensile Test Vehicle
}

\author{
William E. Windes
}

September 2006

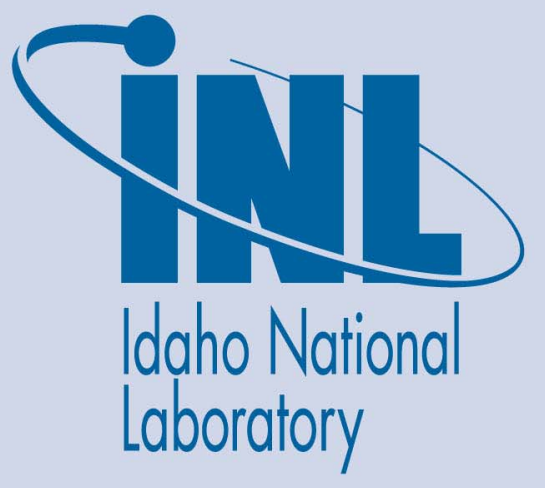

The INL is a U.S. Department of Energy National Laboratory operated by Battelle Energy Alliance 
INL/EXT-06-11951

\title{
Conceptual Design Report for the NGNP Tensile Test Vehicle
}

\author{
William E. Windes
}

September 2006

\begin{abstract}
Idaho National Laboratory
Idaho Falls, Idaho 83415
\end{abstract}

Prepared for the

U.S. Department of Energy

Office of Nuclear Energy

Under DOE Idaho Operations Office

Contract DE-AC07-05ID14517 
This page intentionally left blank. 


\section{Contents}

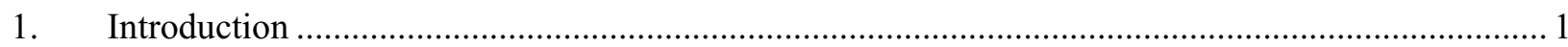

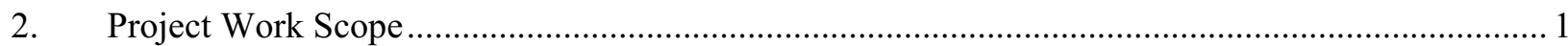

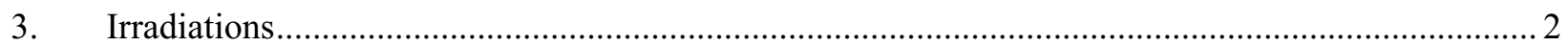

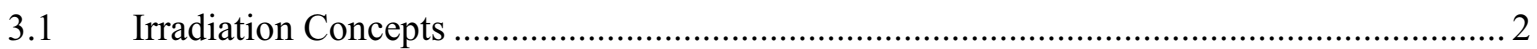

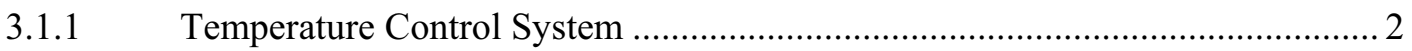

3.1.2 Reactor Irradiations Positions ........................................................................... 4

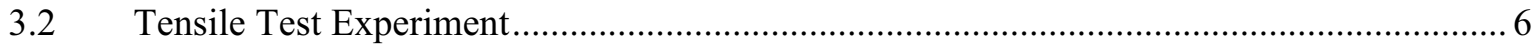

3.2.1 Tensile Loading of Test Train Specimens................................................... 7

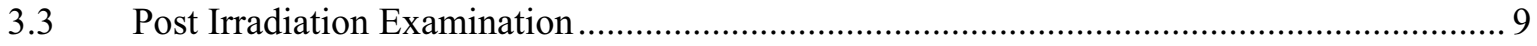

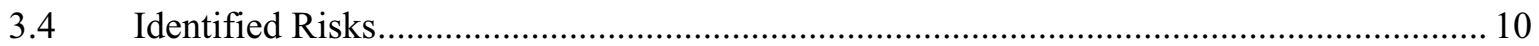

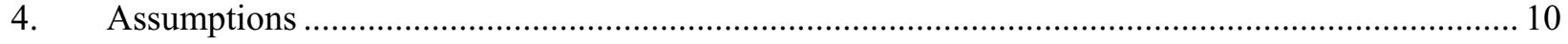

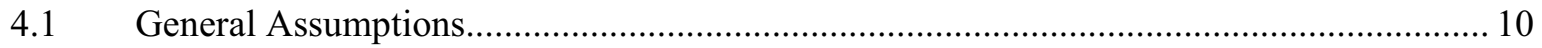

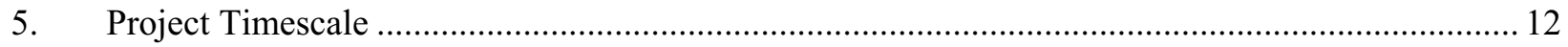

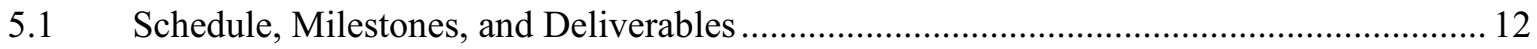

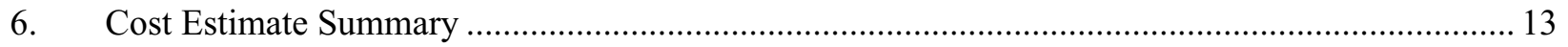

6.1 Flux Trap Tensile Test Experiment Cost Estimate........................................................ 13 


\section{Figures}

Figure 1. Typical Gas Control System Equipment ....................................................................... 3

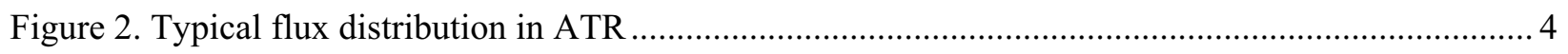

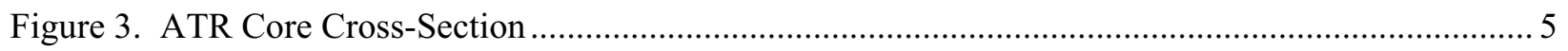

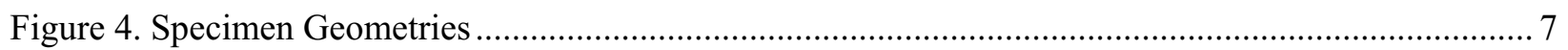

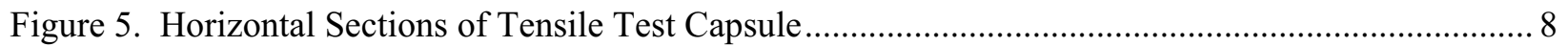

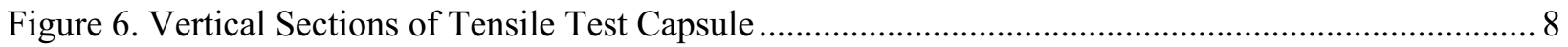

\section{Tables}

Table 1. Number of Test Specimens per Reactor Position .............................................................. 5

Table 2. Average Irradiation Time for Three Reactor Position ............................................................... 6

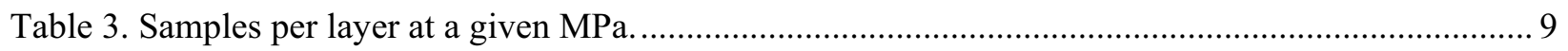

Table 4. ROM estimated costs for an instrumented lead experiment for the NGNP Tensile Test materials14 


\section{Conceptual Design Report for the NGNP Tensile Test Vehicle}

\section{Introduction}

A conceptual design was preformed to determine the feasibility of irradiating silicon carbide fiber reinforced /silicon carbide $\left(\mathrm{SiC}_{\mathrm{f}} / \mathrm{SiC}\right)$ and carbon fiber reinforced /carbon $\left(\mathrm{C}_{\mathrm{f}} / \mathrm{C}\right)$ tensile test specimens for the Next Generation Nuclear Production (NGNP) program. The design was based on the Flux Trap, Large and Small B irradiation positions in the Advanced Test Reactor. The Test Specimens investigated were $50 \% \mathrm{SiC}_{\mathrm{f}} / \mathrm{SiC}$ composites and $50 \% \mathrm{C}_{\mathrm{f}} / \mathrm{C}$ composites. The specimens geometry were either tapered or fillet type dog bone shape, 25 to $35 \mathrm{~mm}$ long with a gauge length of $20 \mathrm{~mm}$, width $6 \mathrm{~mm}$, and $3 \mathrm{~mm}$ thick. The width of the support end of the specimens was 10-12 $\mathrm{mm}$.

The test specimens require finite temperature control from 600 to $1,000{ }^{\circ} \mathrm{C}$. Due to the high temperatures required for the test specimens, the adjacent components will need to be fabricated from composite or graphitic materials. One-third to one-half of the specimens will be unloaded but will have the same geometry and irradiation conditions as the tensile specimens. The desired specimen irradiations damage was $9 \mathrm{dpa}$ and the desired tensile stress limits were from 10 to $30 \mathrm{MPa}$.

One of the design objectives was to load the test train so that single or multiple specimen failures would not compromise the entire test train. This need was realized from previous irradiations where the specimens were all loaded through a single load path. Any specimen failure along the load path resulted in the entire test train to become unloaded. Another design objective was to determine the best irradiation position that would maximize the target space but still provide the neutron flux needed to complete the irradiations in a reasonable amount of time.

A rough order of magnitude cost estimate and schedule was completed based on previous experiments. The corresponding risk assessment was performed to identify possible items that may affect the overall project success. Depending upon how the risks are mitigated, the cost and schedules may be impacted.

\section{Project Work Scope}

The work scope for experiment will be accomplished in the following manner. The project will begin by establishing a design requirements document in concert with the Material Sciences group. This document will include all of the requirements from Material Science personnel to ensure the irradiations will provide their essential data. This document will also include all of the INL requirements necessary to safely irradiate the specimens in the ATR. The next step will be to perform the preliminary design, which will develop the overall concepts and enveloping analyses to ensure that the initial concepts will meet the customer's as well as ATR's requirements. There will be a design review held at the end of the preliminary design. All action items and comments from the review will be resolved and incorporated in the final design. Following resolution of any action items identified in the final design review, the experiment and support system drawings and analyses will be approved. Next, the fabrication of the first experiment components and support systems will be accomplished. After these tasks are completed, the experiment test train will be assembled, and the support and control systems will also be installed in the ATR facility. The experiment will then be inserted in the ATR and irradiated. After the experiment has been irradiated in the ATR for the specified amount of time, it will be removed from the reactor to allow the specimens to undergo disassembly and post irradiation examination. 


\section{Irradiations}

\subsection{Irradiation Concepts}

The purpose of the experiment is to irradiate specimens that are both under a tensile load and in a relaxed or unloaded state. This allows the sponsor to study the tensile effects of the specimens from an irradiation environment. The irradiation, temperature and atmosphere conditions of both the tensile and unloaded specimens will be controlled so that both specimen types are in the same environment.

It was determined that the flux trap positions provide the best environment for this type of testing. This decision was driven primarily by the amount of time that the experiment will need to be in the reactor to reach the desired radiation damage limits. Fortunately the flux trap positions also offer the greatest amount of irradiation space. Unfortunately, these positions are the most expensive to rent. The proposed design could be resized to fit within a Large B position, but this position is not practical unless the dpa requirements are lowered.

After the irradiations have been completed, the test train assembly will be removed from the reactor and placed in the canal for cool down and storage. From the canal area, the capsule section will be removed from the test train and loaded into a commercial cask for shipping. This will require dry loading of the cask where the capsule remains dry through the entire event. A method for performing this operation has been developed for other programs currently underway.

Since the specimens require control of the irradiation temperature within limited specified ranges the irradiation will be performed as instrumented "lead-type" experiments. More detailed descriptions and irradiation conditions of the specimens are included in sections 3.1 and 3.1.1

\subsubsection{Temperature Control System}

An instrumented lead-type experiment offers active temperature monitoring and control of the specimen temperature. The lead-type experiments are attached to piping that exits out through the reactor vessel. Temperature control gas lines and thermocouples are routed from the experiment to control panels through the lead-out piping. This provides precise control of the irradiation temperature $\left( \pm 5^{\circ} \mathrm{C}\right)$ and a temperature history of the specimens at all times during irradiation. This information can remove significant uncertainties and greatly improve the data quality achieved from the experiments.

There is a vast amount of experience in conducting similar type temperature-controlled experiments at ATR. A very good example is the British Magnox graphite irradiation experiment that was conducted in 2002 with a cover gas environment for the specimens that was separate from the temperature control system. In addition, other active temperature-controlled experiments have been performed in ATR for a number of different programs. Active temperature-controlled experiments were routinely conducted in the Materials Test Reactor and the Engineering Test Reactor at the Reactor Technology Complex from the 1950's through the 1970's.

Active temperature control of ATR lead-type experiments is achieved by controlling the heat transfer across a narrow precision-machined insulating gas gap between the specimen holder, heat shields and the outer capsule boundary, which separates the test vehicle internals from the relatively cool (approximately $60^{\circ} \mathrm{C}$ ) ATR primary coolant. Mass flow controllers are used to blend a mixture of two inert gases with differing thermal conductivities based upon feedback from thermocouples located within the experiment capsules. The gases used in the experiment may be either helium and neon or possibly helium and argon (if the temperatures are difficult to achieve). Typically neon is used due to its low 
neutron activation; however, argon may be used if additional temperature control band is needed. Figure 1 shows the typical components.

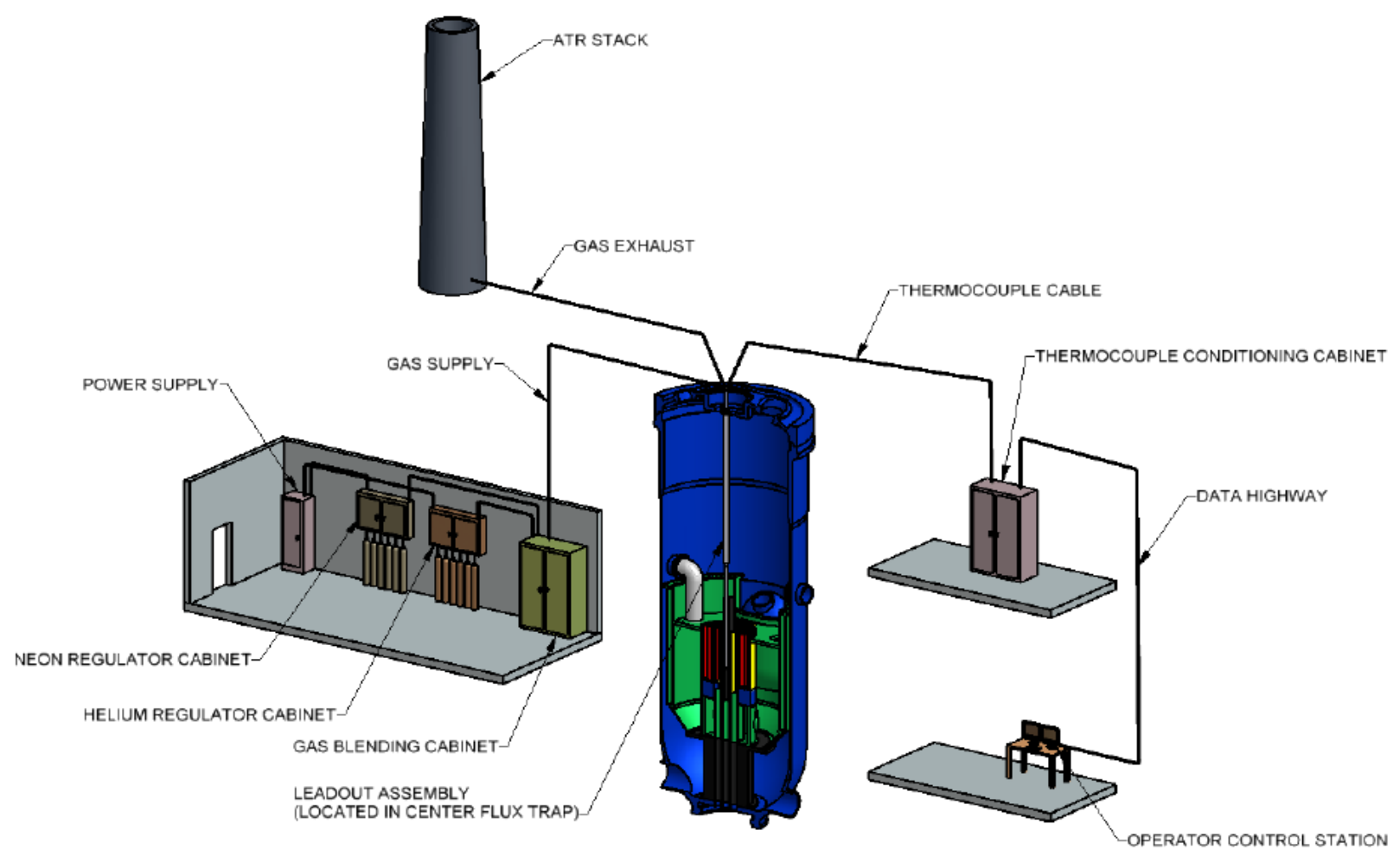

Figure 1. Typical Gas Control System Equipment

ATR temperature controlled experiments are designed by closely integrating the mechanical test train design with both the reactor physics analysis (using the Monte Carlo Neutral Particle [MCNP] analysis code) and the thermal analysis (using ABAQUS) of the experiment. Once an experiment concept has been developed with nominal dimensions and material types, then a reactor physics model is constructed and the calculations are performed using MCNP. The calculated neutron reaction and gamma heating values from the reactor physics analysis are then input to the thermal analysis to predict the temperatures in the specimens. Based upon the thermal analysis results, the necessary changes are made to the design and the whole process is repeated until the specified temperatures are attained. The options available for achieving the desired temperatures are the insulating gas gap width, the amount of mass in the experiment for gamma heating, and the types and relative mixtures of the gases in the gas gap. The amount of mass in the experiment may be adjusted by using materials with different densities and/or by changing the location and relative dimensions of the experiment components. Different insulator gases (neon, argon, etc.) may also be used to increase or decrease the gas gap width.

The axial temperature variation across the specimens will be determined by the thermal conductivity of the specimens, the axial flux distribution across the core, and the actual design of the capsules. The axial flux profile is relatively flat for approximately $760 \mathrm{~mm}$ of core height centered about the core mid-plane. This area generally provides uniform temperature distribution, and the proposed irradiation concepts for the experiment fit well within this window. See Figure 2 below for a typical flux distribution in an ATR flux trap position. 


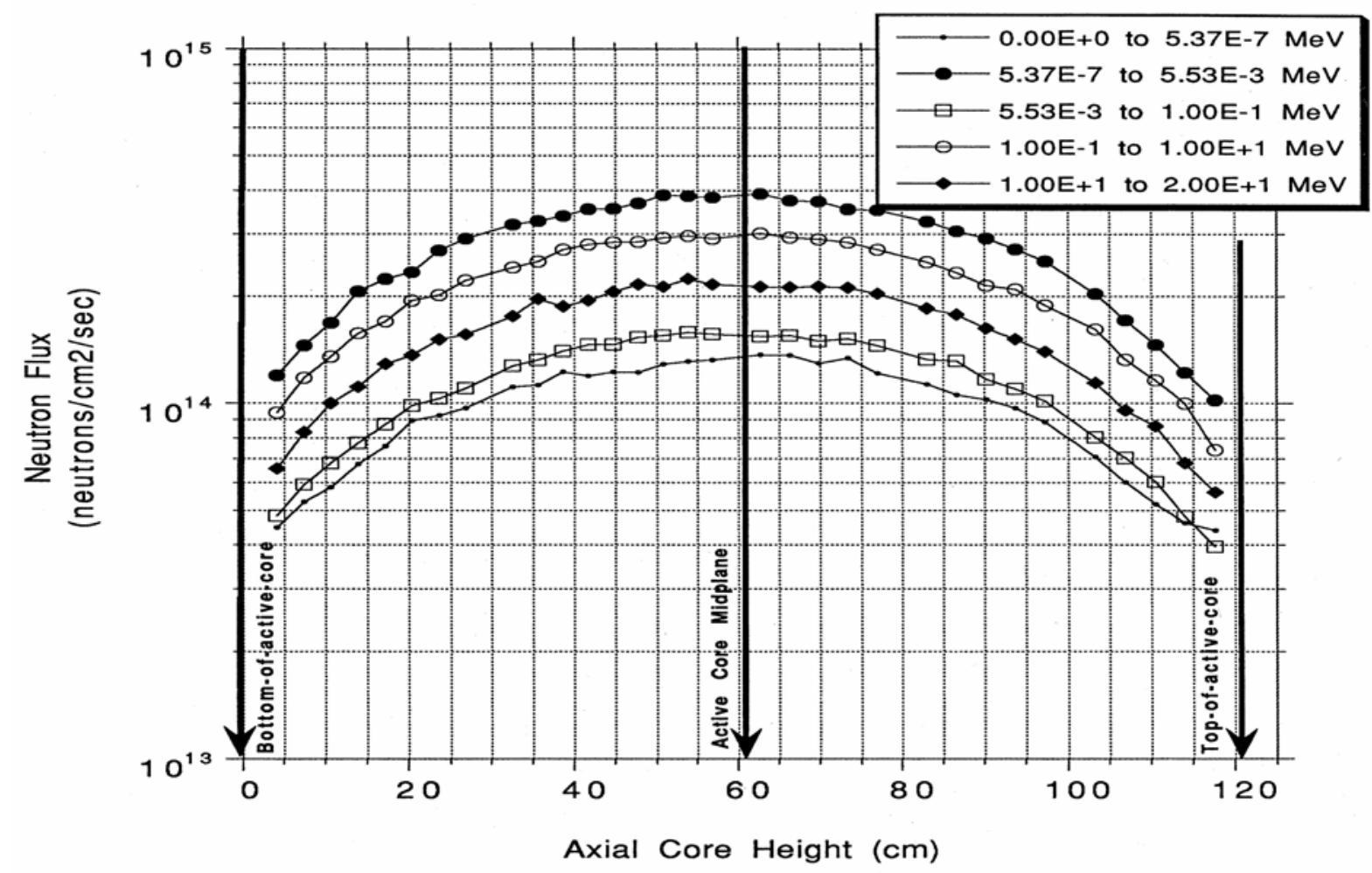

Figure 2. Typical flux distribution in ATR

\subsubsection{Reactor Irradiations Positions}

Three different reactor positions were considered for this irradiation, the Flux Traps, and the Large and Small B positions. The Small B positions are $22.2 \mathrm{~mm}$ in diameter, the Large B positions are 38.1 $\mathrm{mm}$ in diameter, and the Flux Traps are $76.2 \mathrm{~mm}$ in diameter. All three positions have an active core length of 1.22 meters. Figure 3 shows a cross section of the ATR core, with the various irradiation positions labeled, including the Flux Trap (in-Pile Tube) positions. 


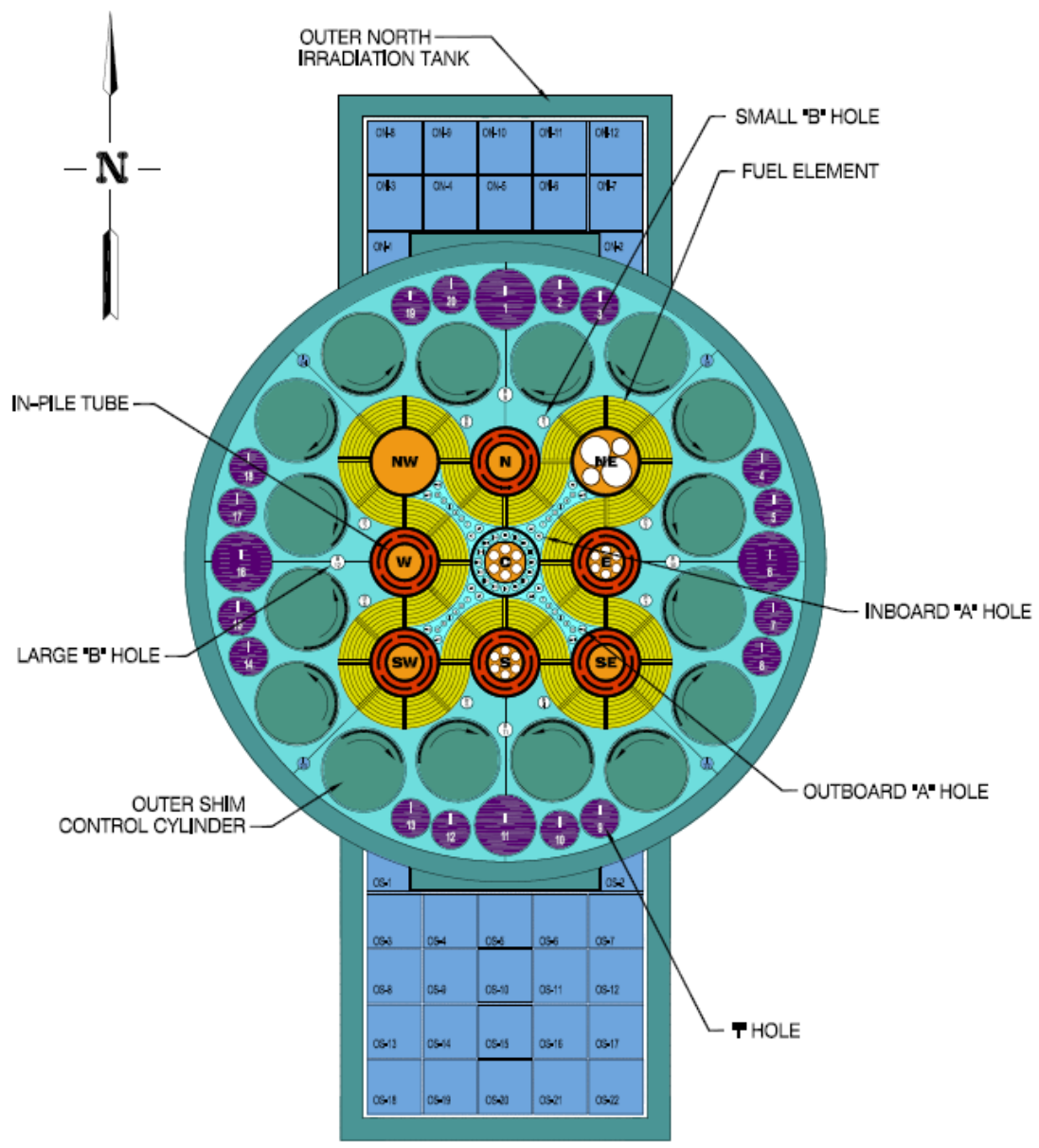

Figure 3. ATR Core Cross-Section

The available space for specimens in each of the reactor positions is determined by the size of the push rods, the heat shield and capsule thickness, the temperature control gas annulus width, and the space needed for thermocouples and gas lines. Table 1 shows the number of specimens that can fit in each of the irradiation positions based on the available space. The sample sizes used in these figures have $12 \mathrm{~mm}$ wide by $3 \mathrm{~mm}$ thick end pieces. In addition to the space limitations, there is limited space in the leadout piping above the core section for the equipment needed to load the specimens. At higher tensile loads, the available tensile load output of this equipment will limit the number of specimens. This is addressed further in section 3.2.1.

Table 1. Number of Test Specimens per Reactor Position

\begin{tabular}{|l|c|}
\hline \multicolumn{1}{|c|}{ Reactor Position } & Number of Test Specimens \\
\hline Small B Position & 1 \\
\hline Large B Position & 3 \\
\hline Small Flux Trap & 18 \\
\hline
\end{tabular}

The neutron physics results from the NGNP Advanced Graphite Capsule (AGC) were used to determine the resident time for the tensile test. Dose values for $\mathrm{SiC}$ are generally $1 \mathrm{dpa}=1 \times 10^{21} \mathrm{n} / \mathrm{cm}^{2}$ in 
a thermal LWR which is about $75 \%$ of a graphitic or $\mathrm{C}_{\mathrm{f}} / \mathrm{C}$ composites material. Since the types of materials and dimensions of the conceptual tensile test experiment are similar to the AGC test capsule materials the neutron physics are assumed to be similar. The AGC capsule is scheduled to go in the south flux trap with an average fast flux $(<0.1 \mathrm{MeV})$ of about $2.7 \times 10^{14}$ neutrons $/ \mathrm{cm}^{2}$-sec yielding an average radiation material damage rate of $0.018 \mathrm{dpa} /$ day. Using this rate for the tensile test, it will take 556 effective full power days (EFPD) to reach a maximum material damage goal of $10 \mathrm{dpa}$. Because the reactor operates about $60 \%$ of the time, it will require 780 days or approximately 2.1 years to complete the total irradiations cycle. Based on the published fast flux ratios for the other positions, it will require approximately 2.6 years to complete the maximum irradiation in a small B position and 13 years in a large B position. Table 2 shows the approximate operating time for the different positions to reach 1, 5, and $10 \mathrm{dpa}$. However, the actual irradiation times will be determined by using computer codes and the actual reactor operating power history at the specific irradiation position.

Table 2. Average Irradiation Time for Three Reactor Position

\begin{tabular}{|l|c|c|c|}
\hline \multicolumn{1}{|c|}{ Average Irradiation Time } & $\mathbf{1} \mathbf{~ d p a}$ & $\mathbf{5} \mathbf{~ d p a}$ & $\mathbf{1 0}$ dpa \\
\hline Small Flux Trap & 0.21 years & 1.1 years & 2.1 years \\
\hline Small B Position & 0.26 years & 1.3 years & 2.6 years \\
\hline Large B Position & 1.3 years & 6.5 years & 13 years \\
\hline
\end{tabular}

The long irradiations time associated with the large B position dismissed this position as a candidate for the tensile test irradiation as the small number a specimens dismissed the small B position. The Large B position could be utilized for irradiations for lower material damage testing $(<2 \mathrm{dpa})$. The flux traps offer the most space and the highest fluence but they are more expensive than the other reactor positions and the future availability would need to be determined.

The Center, East and South flux trap positions do not contain in-pile tubes and are therefore the logical choices for this type of testing. A lead-out assembly has not been installed in a flux trap position, but the NGNP AGC testing is scheduled to install one in the South Flux Trap. The design of the AGC experiment was started in 2005, and is scheduled for completion along with initial experiment fabrication by the end of 2006. Irradiation of the first experiment is expected to begin in late 2007. These tests are scheduled to take place through 2009. The Advanced Fuel Cycle Initiative (AFCI) and Light Water Reactor (LWR) fuel concepts began using the East Flux Trap for irradiation test in July 2003, and plans to continue using the ATR throughout the duration of the program. The AFCI has currently planned irradiations for ATR through at least 2010, and is continuing to identify additional testing for ATR into the future. The Materials and Fuels Complex (MFC) is developing new low enriched fuels to replace the high enriched fuel used in research and test reactors. This is the Reduced Enrichment for Research and Test Reactors (RERTR) Fuel Irradiations Program. RERTR full size fuel plate experiments are planned for the Center Flux Trap. The first full size fuel plate experiment will be inserted in ATR in January 2007 and are expected to be completed in Novmber 2007. The planned use of the Center Flux Trap for the RERTR program be completed before a NGNP Tensile Test experiment would be ready for irradiation. The NGNP Tensile Test experiment conceptual design is therefore based on the Center Flux Trap position.

\subsection{Tensile Test Experiment}

The approach for NGNP Tensile Test experiment conceptual design would be to place a combination of silicon carbide fiber reinforced /silicon carbide $\left(\mathrm{SiC}_{\mathrm{f}} / \mathrm{SiC}\right)$ and carbon fiber reinforced /carbon $\left(\mathrm{C}_{\mathrm{f}} / \mathrm{C}\right)$ composite tensile specimens in the region of the reactor core centerline. The specimens 
would be either the typical dog bone shape or have tapered ends as shown in Figure 4. One-third to onehalf of the specimens would be unloaded. The remaining specimens would be under an axial load. The desired axial load for these specimens is from 10 to $30 \mathrm{MPa}$.

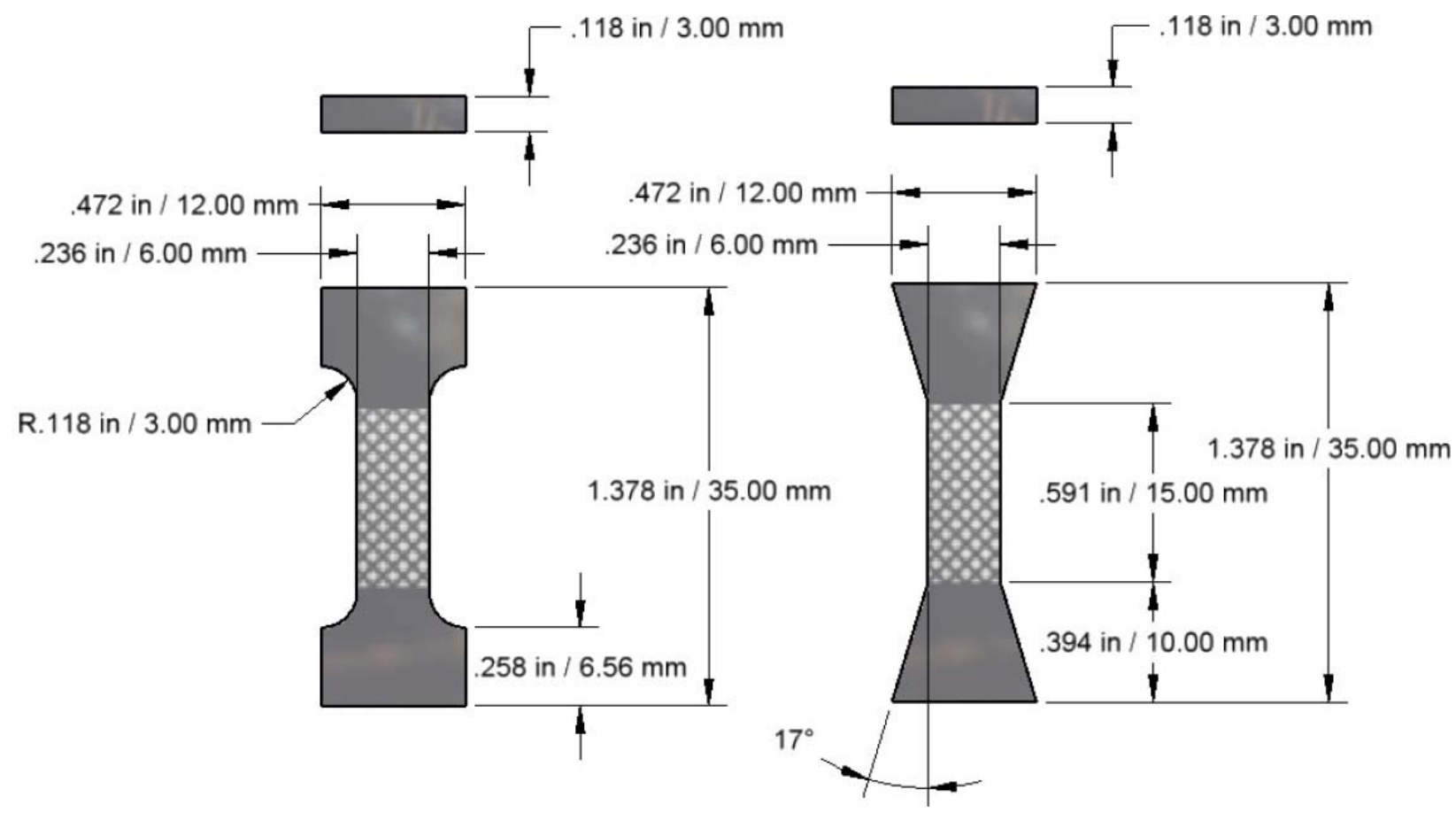

Figure 4. Specimen Geometries

\subsubsection{Tensile Loading of Test Train Specimens}

The experiment test train will consist of seven separate capsules that will each contain 18 specimens. Four of the capsules will contain tensile loaded specimens (72 total) with the other three containing unloaded (relaxed) specimens (54 total). The specimen capsules will alternate between tensile and relaxed specimens. The tensile loading for each of the tensile capsules will be independent from one another. This will be accomplished by placing the specimens in a holder, fixing the top of the holder in place, and pushing down on the bottom holder with a pneumatic or hydraulic cylinder (ram). The cylinders would be located above the core of the reactor to minimize radiation damage. The load from the cylinder would be transmitted to the bottom specimen holder through push rods. The push rods will need to be fabricated from either graphite or composite material to withstand the high temperatures. A load cell will be placed inline with each of the push rods to measure the tensile load. This will eliminate uncertainties with thermal growth in the push rods and the output of the load cylinders. A horizontal cross-section and a vertical section of the proposed capsule is shown in Figure 5 and Figure 6. 


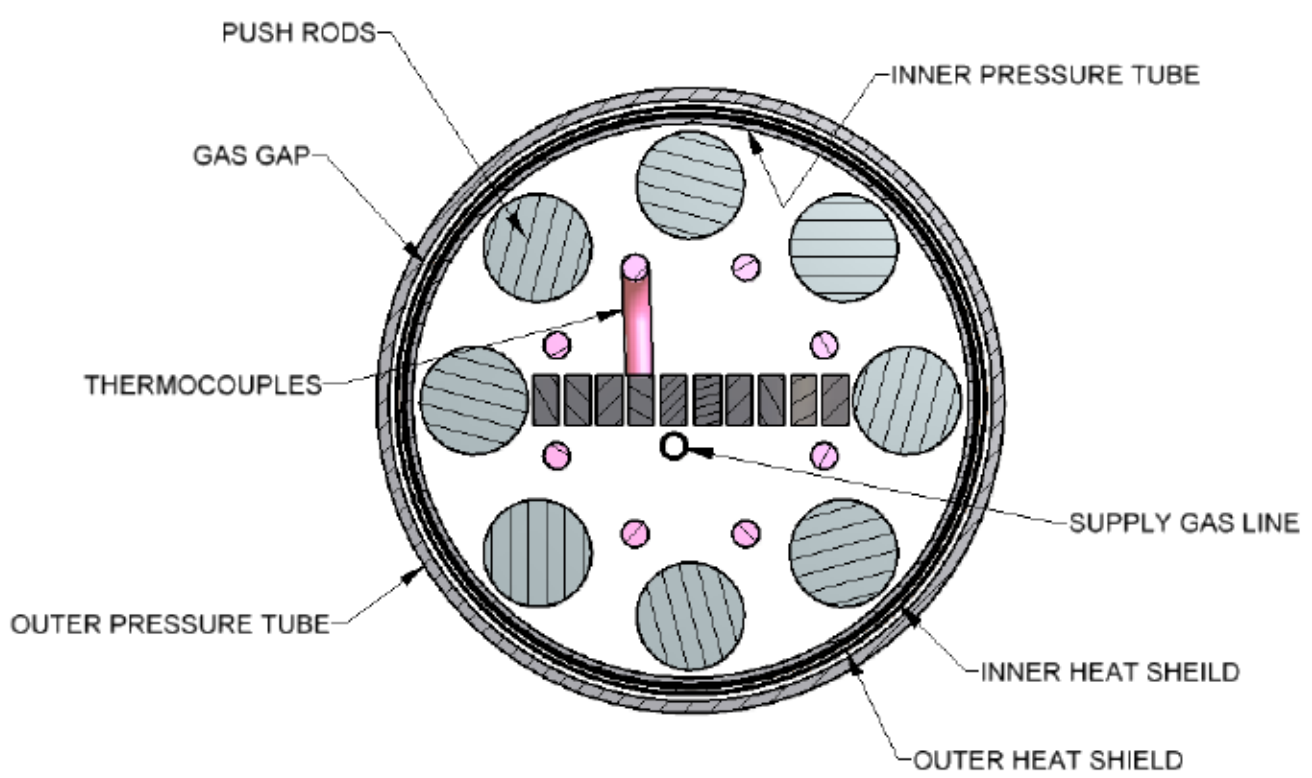

Figure 5. Horizontal Sections of Tensile Test Capsule

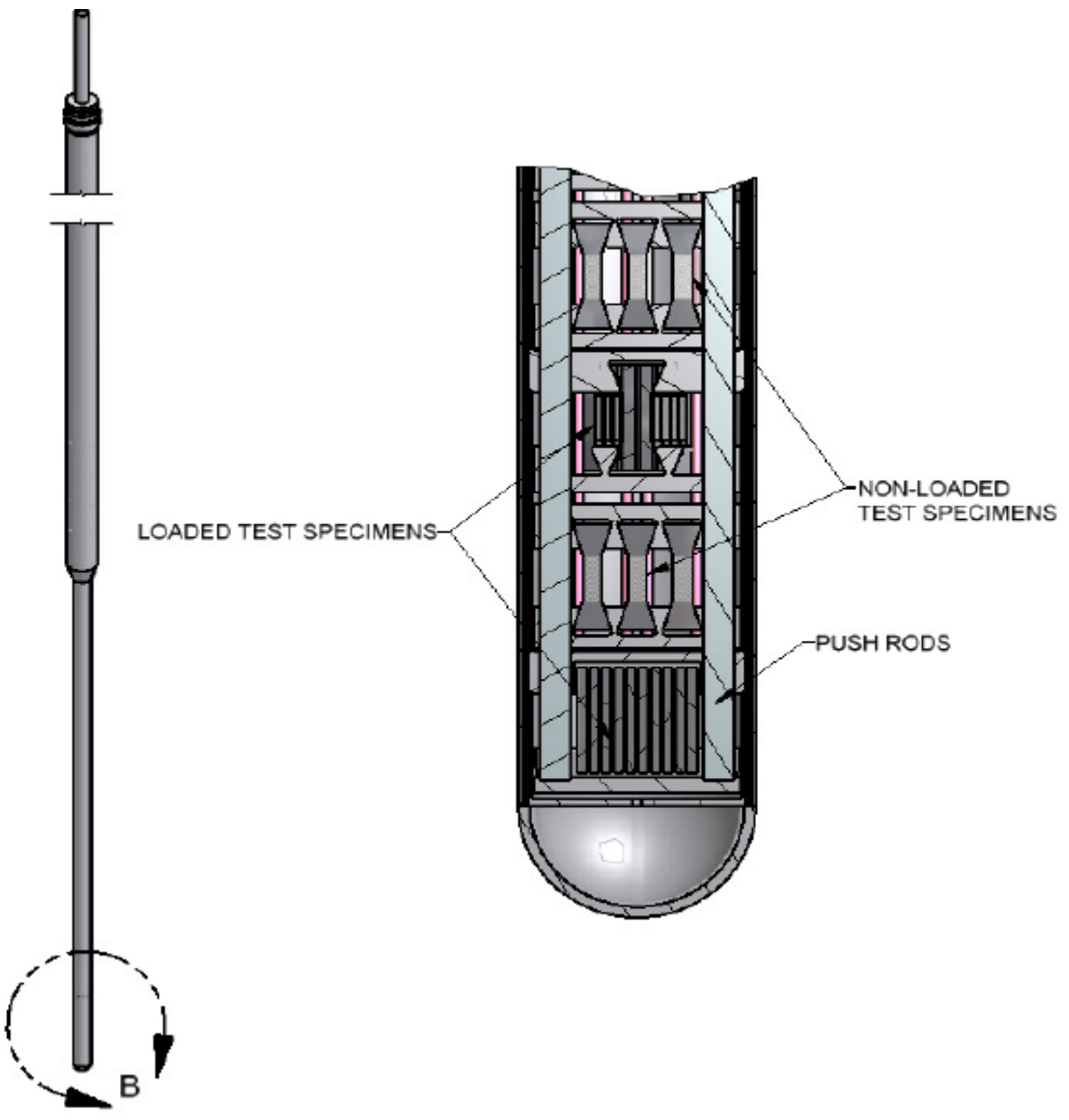

Figure 6. Vertical Sections of Tensile Test Capsule 
The loaded and relaxed specimen layers are alternated through the core centerline. The specimens cover approximately $330 \mathrm{~mm}$ inches of the approximate $760 \mathrm{~mm}$ length of core that has the flattest neutron profile. This only accounts for $27 \%$ of the active core length (1.22 meter). The number of tensile loaded specimens is limited by the physical space above core for the cylinders and push rods and by the cylinder output force. The output force from the cylinders is determined by the cylinder size and supply pressure.

The pneumatic cylinders located in the equipment searches with a physical diameter of $25.4 \mathrm{~mm}$ are rated at $1.7 \mathrm{MPa}$ with a output multiplier of 2.4 have a maximum output of $600 \mathrm{lb}_{\mathrm{f}}$. Comparable sized hydraulic cylinders have an output of $2355 \mathrm{lb}_{\mathrm{f}}$. Based upon the specimen gauge sections of $3 \mathrm{~mm} \mathrm{x}$ $6 \mathrm{~mm}$, the cross-sectional area for each test specimen is $1.8 \times 10^{-5} \mathrm{~m}^{2}$. Using this cross-sectional area for the test specimens, the load on a single specimen capable of producing desirable applied stresses is:

$1 \mathrm{MPa}$ (on single sample) $=4.03 \mathrm{lb}_{\mathrm{f}}$

$5 \mathrm{MPa}$ (on single sample) $=20.15 \mathrm{lb}_{\mathrm{f}}$

$10 \mathrm{MPa}$ (on single sample) $=40.3 \mathrm{lb}_{\mathrm{f}}$

$30 \mathrm{MPa}$ (on single sample) $=121 \mathrm{lb}_{\mathrm{f}}$

To achieve a maximum applied stress of $30 \mathrm{MPa}$ over an entire sample layer, the pneumatic cylinder can only load 4 samples in a test layer while the hydraulic cylinders can achieve 18 samples (see Table 3). If the load is reduced to a more manageable $10 \mathrm{MPa} /$ sample the pneumatic cylinders should be capable of loading a sufficient number of samples (12 samples/layer) even in the larger flux trap sample configuration. Additional unloaded specimens could be placed in the experiment test train as need.

Table 3. Samples per layer at a given MPa.

\begin{tabular}{|l|l|l|}
\hline Stress (one sample) & $\begin{array}{l}\text { Pneumatic cylinders } \\
\left(@ \mathbf{8 0 \%} \text { of 600 } \mathbf{~ b}_{\mathbf{f}} \text { Capacity }\right)\end{array}$ & $\begin{array}{l}\text { Hydraulic cylinders } \\
\left(\mathbf{0} \mathbf{8 0} \text { of 2355 } \mathbf{~ b b}_{\mathbf{f}} \text { Capacity }\right)\end{array}$ \\
\hline $1 \mathrm{MPa}$ & 118 samples/layer & 464 samples/layer \\
\hline $5 \mathrm{MPa}$ & 24 samples/layer & 93 samples/layer \\
\hline $10 \mathrm{MPa}$ & 12 samples/layer & 46 samples/layer \\
\hline $30 \mathrm{MPa}$ & 4 samples/layer & 15 samples/layer \\
\hline
\end{tabular}

The experiment will be an instrumented lead-type with separate active temperature monitoring and control of each capsule. All capsules will share a single temperature control gas. The temperature control gas, which will consist of a custom blended mixture of inert gasses, will be flowing in the outer region or temperature control gas annulus between the specimen holder and the outside capsule wall. The temperature control gas lines and thermocouples will be routed through the specimen holders. A minimum of two thermocouples per capsule will be used to monitor and control the temperature of the specimens. The capsules will also contain passive dosimetry (flux wires) for post-irradiation analysis to determine the precise fluence values. Several different flux wires located either in or around the specimen holder will be used to provide both the fast and thermal neutron fluence.

\subsection{Post Irradiation Examination}

Once the irradiation phase has been completed on each experiment, the test train will be shipped for disassembly and Post Irradiation Examination (PIE). A commercial cask (GE-2000) will be used that can interface with the Materials and Fuel Complex. 


\subsection{Identified Risks}

Risk that were identified during this study are listed below. Mitigation of these risks should be considered during the next phase of the design.

1. High Temperatures: A thermal analysis of the proposed design has not been performed. The capsule components will need to be fabricated from composite materials that can withstand high temperatures. Modifications to the proposed designed may be needed to size the temperature control gas gap for proper temperature control. This dimension will not be known until reactor physics and thermal analysis have been performed.

2. Fabrication Tolerances: For each of the specimens to be loaded evenly, the specimens, specimen carriers, specimen holders and push rods will need to be fabricated to tight tolerances. If one the specimens is shorter than the others, that individual specimen will take to load intended for all the specimens in the holder. This could cause premature specimen failure or result in incorrect postulations in the test results.

3. Push Rods: The push rods will need to be supported to prevent bowing. Since part of the push rods will be in the high neutron flux, a thorough understanding of the heat and neutron interactions will need to be known.

4. Capsule Material Fabrication: The materials adjacent to the specimens will need to withstand high temperature and neutron fluence, and be fabricated to tight tolerances to provide a heat transfer path to the temperature control gas. The geometries needed accommodate the specimens and push rods will be complicated.

5. Hydraulic Fluid: Use of hydraulic fluids has not been used in test train designs in the part at ATR. There are fluids that are compatible with the primary system that may be approved for use.

6. Specimen Temperatures: Specimen temperatures in the $1000^{\circ} \mathrm{C}$ range have not been run in the ATR. Current experiments plan to operate in the $600^{\circ}$ to $800^{\circ} \mathrm{C}$ range.

7. Reactor Top: There is limited space available in the reactor top area and limited penetrations to route gas lines, thermocouples and hydraulic or pneumatic lines from the reactor vessel to the equipment corridors. Core drilling of the three foot thick shield walls may be necessary if the present penetrations are filled by the current experiment programs.

\section{Assumptions}

The assumptions used in establishing the timescales and costs for the project activities have been identified and are listed below.

\subsection{General Assumptions}

Assumptions that apply to the experiment and the project in general have been identified and are listed below.

- Specimens will be loaded in an array with a constant gas gap and material mass in each capsule. This arrangement does not compensate for thermal gradients at the outside ends of the test train. 
- The irradiation positions desired for these experiments will be available when needed.

- Active temperature monitoring and control is required, and a new gas temperature control system will be needed for this experiment.

- At least two thermocouples will be included in each capsule. The specimen temperatures will need to be extrapolated as the thermocouples will need to be placed out of the hot regions of the experiment.

- Instrumentation (thermocouples) located within the experiment that fails during irradiation will not be replaced.

- The temperature will be maintained within $\pm 5^{\circ} \mathrm{C}$ of the specified temperature during irradiation.

- Neutron flux measurement wires for both the thermal and fast spectrum will be needed.

- Flux wires will be analyzed only at the end of irradiation.

- ATR's operating schedule is assumed to be a nominal seven reactor cycles per calendar year with availability (percentage of operating time per year) of $60 \%$. The full power days will vary depending on the exact operating schedule during each year.

- Occasional short high power cycles may increase the power in the area adjacent to the experiment, and if the increased power will adversely affect the experiment, then the experiment may be removed during the short cycle. These removal and re-insertion costs are not included in this estimate.

- A mock-up test for each reactor irradiation position will serve as both the nuclear back-up test and can also be used to verify the reactivity worth of the experiment in the ATR Critical (ATRC) facility. This estimate includes the costs and schedule for an ATRC test.

- A mockup of the equipment used to tensile load the specimens will be needed.

- All work will be performed in accordance with INL safety processes, quality requirements, and work control procedures.

- The costs for the irradiations are expressed in INL Fiscal Year 2006 dollars with an annual cost escalation of $3 \%$. The $3 \%$ escalation is historically what has been used in the Irradiation Unit charges, but is subject to change. The other charges for labor and materials will be escalated as future labor rates are set at INL. 


\section{Project Timescale}

The Milestones and Deliverables for each task have been identified and listed below. Each project Milestone and associated date is identified with a list of Deliverables. Mismatches in the ATR operating cycles may cause delays in the insertion of the experiments.

\subsection{Schedule, Milestones, and Deliverables}

Milestone 1: Design Requirements - 6 weeks after funding is received at INL (Project Month 2)

Deliverable:

- Final Draft Test Train Design Requirements Document

Milestone 2: Preliminary Design Review_Project Month 6

Deliverables:

- Preliminary Experiment Test Train Engineering Drawings

- Preliminary Temperature Control System Engineering Drawings/Software

- Preliminary Tensile Load Control System Engineering Drawings/Software

- Preliminary Thermal Analysis

- Preliminary Neutronics Analysis

- Preliminary Stress/Seismic Analysis

- Preliminary Design Review Report

Milestone 3: Final Design Review—Project Month 10

Deliverables:

- Final Draft of Test Train Engineering Drawings

- Final Draft of Temperature Control System Drawings/Software

- Final Draft of Tensile Load Control System Engineering Drawings/Software

- Final Draft of Thermal Analysis

- Final Draft of Neutronics Analysis

- Final Draft of Stress/Seismic Analysis

- Final Design Review Report

Milestone 4: Mockup Testing of Tensile Load Equipment—Project Month 14

Deliverables:

- Report of Mockup Test 
Milestone 5: Start of Fabrication—Project Month 15

Deliverables:

- $\quad$ Signed and Released Test Train Engineering Drawings

- Signed and Released Temperature Control and Tensile Load Control System Drawings/Software

- Signed and Released Final Analyses

Milestone 6: Start of Experiment Irradiation-Project Month 22

Deliverables:

- Completed and Assembled Tensile Test Train

- Completed ATRC Experiment Irradiation and Data

- Completed and Tested Temperature Control System

- Completed and Tensile Load Control System

- Approved Experiment Safety Assurance Package

Milestone 6: Complete Irradiation of Tensile Experiment—Project Month 47

Deliverables:

- Specimens Irradiated for Approximately 556 EFPD in ATR.

- Preliminary As-Run Analysis of Specimens

Milestone 12: Project Close-out—Project Month 50

Deliverables:

- Final Project Report

- Project Documentation Close-out

\section{Cost Estimate Summary}

The rough order of magnitude costs for the experiment have been estimated and are identified below. A preliminary risk screening was performed to identify uncertainties in the cost estimates. Appropriate contingencies have been added to account for these uncertainties. This estimate is based on a single standalone experiment.

\subsection{Flux Trap Tensile Test Experiment Cost Estimate}

The summary ROM estimated costs for an instrumented lead experiment for the NGNP Tensile Test materials are listed below. These costs are not informal costs for Project Controls purposes. They are offered as part of this report for estimation purposes only to give the Material and Controls group an understanding of the costs associated with irradiation test at the ATR. 
The activities for each task are listed to provide some insight into the activities needed. Following the cost estimate summary is a breakdown of the activities with the approximate time and costs necessary to complete each task. The labor and material costs will be similar for either a Flux Trap or Large B position. These costs do not include the reactor usage (irradiation unit (IU) charges). The estimated IU charges for the Flux Trap and Large B positions are given below. Again, the IU costs are expressed in INL Fiscal Year 2006 dollars with an annual cost escalation of 3\%. The $3 \%$ escalation is historically what has been used in the Irradiation Unit charges, but is subject to change.

Table 4. ROM estimated costs for an instrumented lead experiment for the NGNP Tensile Test materials

\begin{tabular}{|l|c|c|}
\hline & Cost per Effective Full Power Day & $\begin{array}{c}\text { Cost for 1 year irradiation @ 60\% } \\
\text { Reactor Utilization }\end{array}$ \\
\hline $\begin{array}{l}\text { Center Flux Trap Position } \\
\text { (Based on 27 MW Lobe Power }\end{array}$ & $\begin{array}{c}\$ 12,929 / \mathrm{EFPD} \\
\text { Based on 24.5 MW lobe Power }\end{array}$ & $\$ 2,831,410$ \\
\hline $\begin{array}{l}\text { Large B Position } \\
\text { (Based on 25 MW Power) }\end{array}$ & $\begin{array}{c}\$ 83.7 / \mathrm{EFPD} \\
\text { Based on 24 MW lobe Power }\end{array}$ & $\$ 18,330$ \\
\hline
\end{tabular}

\section{ACTIVITY/TASK}

$\operatorname{COSTS}(\$ K)$

Preliminary Design and Review

1,217

Draft experiment drawings

ATR Tensile Test Train

ATRC reactivity measurement capsules

Preliminary supporting analyses

Thermal hydraulic

Reactor physics

Stress, seismic \& vibration

Experiment safety

Draft temperature control system drawings

Draft tensile loading system drawings

Preliminary design review and report

Project management \& technical support

Final Design and Review

880

Completed experiment drawings

ATR Permeation Test Train

ATRC capsules

Final supporting analyses

Thermal hydraulic

Reactor physics

Stress, seismic \& vibration

Experiment safety

Completed temperature control system drawings

Completed permeation experiment purge system drawing

Final Design Review and Report

Project management \& technical support

Fabrication and Assembly

Fabrication work packages

Development of special processes (brazes, plating, etc.) 
Assembly Procedures

Fabricate and Assemble test train

Installation \& Testing of Temperature Control System

Installation \& Testing of permeation experiment purge system

Project management \& technical support

Irradiation

ATRC Test Plan, experiment operation, \& data reduction

Training of operators on control system

Reactor Insertion Procedures

Experiment handling

Reactor irradiation charges

Reactor operator support

Experiment engineering support

As-Run Analysis for temperature and neutron damage

Irradiation reports

Project management \& technical support

\section{Handling and Packaging}

442

Two experiment transfers to Canal (1 for each test rig)

Procedures for disassembly

Canal disassembly to ship for PIE (twice)

Canal tooling

ORIGEN analysis to ship for PIE (twice)

Cask rental and shipping (twice)

Flux Wire Measurements (twice)

Project management \& technical support 


\section{Preliminary Design and Review}

Internal Use Only

\section{Discipline/Task}

Design Requirements

Mech. \& Elect. Engr

Mechanical Engineering/Design

Tensile Test Train

ATRC Capsules

Tensile Loading System

Temperature System

Drafting

Electrical Engineering/Design

Temperature System

Tensile Loading System

Experiment Capsules

Drafting

Analysis

Thermal/Hydraulic

Reactor Physics

Stress/Vibration

Safety/ESAP

INL Design Review

12 Reviewers for

Approx. 2 days each

Project Management and

Reactor Interface (6 months)

Project Manager

Technical Support

Admin Support

Travel
Labor Hours

(a) Hourly rate

380@150/hr
Material Total

Costs (\$K) Costs (\$K) 640@\$150/hr

100@\$150/hr

640@\$150/hr

300@\$150/hr

400@\$75/hr

300@\$150/hr

640@\$150/hr

75@\$150/hr

400@\$75/hr

400@\$150/hr

500@\$170/hr

200@\$150/hr

160@\$150/hr

$250 @ \$ 150 / \mathrm{hr}$

800@\$150/hr

250@\$150/hr

200@\$80/hr
96.0

15.0

96.0

45.0

30.0

45.0

96.0

11.3

30.0

60.0

85.0

30.0

24.0

37.5

5.0

125.0

37.5

16.0

$20.0 \quad 20.0$

956.3

191.3

34.4

35.5

DOE FAC (3\%) 


\section{Final Design and Review}

Internal Use Only

\section{Discipline/Task}

Mechanical Engineering/Design

Tensile Test Train

ATRC Capsules

Tensile Loading System

Temperature System

Drafting

Mockup Test

Mech. Engr.

Elec. Engr.

Drafting

Electrical Engineering/Design

Temperature System

Tensile Loading System

Experiment Capsules

Drafting

Analysis

Thermal/Hydraulic

Reactor Physics

Stress/Vibration

Safety/ESAP

INL Design Review

12 Reviewers for

2 days each

Project Management and

Reactor Interface (4 months)

Project Manager

Technical Support

Admin Support
Labor Hours
(a) Hourly rate

Material

Costs (\$K) Costs (\$K) 480@\$150/hr

100@\$150/hr

480@\$150/hr

200@\$150/hr

320@\$75/hr

200@\$150/hr

100@,\$150/hr

200@\$75/hr

$200 @ \$ 150 / \mathrm{hr}$

480@\$150/hr

75@\$150/hr

340@\$75/hr

$180 @ \$ 150 / \mathrm{hr}$

200@\$170/hr

$100 @ \$ 150 / \mathrm{hr}$

260@\$150/hr

250@\$150/hr

400@\$150/hr

160@\$150/hr

$120 @ \$ 80 / \mathrm{hr}$
37.5

72.0

15.0

72.0

30.0

24.0

30.0

15.0

15.0

30.0

72.0

11.3

25.5

30.0

51.0

15.0

45.0

65.0

24.0

$1.5 \quad 11.1$

Subtotal

690.4

Contingency (20\%)

138.1

Safeguards \& Security (3\%)

24.9

DOE FAC (3\%)

25.6 


\section{Fabrication and Assembly}

Internal Use Only

\section{Discipline/Task}

Experiment Fabrication

Machinist

Welder

Crafts Planning

Engineering Support

TTAF Experiment Assembly

Engr. Procedures

Tech's (Development)

Tech's (Assembly)

QA Inspector

Engr. Support

ATRC Test Fabrication

Machinist

Welder

Crafts Planning

Engineering Support

TTAF ATRC Test Assemblies

Engr. Procedures

Technicians

QA Inspector

Engr. Support
Labor Hours
(a) Hourly rate

$1000 @ \$ 80 / \mathrm{hr}$

300@\$80/hr

160@\$80/hr

$160 @ \$ 150 / \mathrm{hr}$

$80 @ \$ 150 / \mathrm{hr}$

$160 @ \$ 100 / \mathrm{hr}$

400@\$100/hr

260@\$80/hr

260@\$150/hr

120@\$80/hr

60@\$80/hr

60@\$80/hr

80@\$150/hr

$50 @ \$ 150 / \mathrm{hr}$

$100 @ \$ 100 / \mathrm{hr}$

$50 @ \$ 80 / \mathrm{hr}$

$50 @ \$ 150 / \mathrm{hr}$

$320 @ \$ 150 / \mathrm{hr}$

320@\$80/hr

500@\$80/hr

320@\$150/hr

400@\$80/hr

400@\$80/hr

Fitters

Welders

Tensile Loading System (1 each)

Elect. Engr. Support

Instrument Tech's

Electricians

Mech. Engr. Support

Fitters

Welders
$320 @ \$ 150 / \mathrm{hr}$

320@\$80/hr

300@\$80/hr

320@\$150/hr

400@\$80/hr

400@\$80/hr

\section{Material Total \\ Costs (\$K) Costs (\$K)}

2000.0

180.0

24.0

12.8

24.0

12.0

16.0

40.0

20.8

39.0

1000.0

19.6

4.8

4.8

12.0

7.5

10.0

4.0

7.5

48.0

$75.0 \quad 100.6$

$50.0 \quad 55.0$

48.0

$75.0 \quad 107.0$

$15.0 \quad 47.0$

175.6

223.6

25.6

24.0

48.0

32.0

32.0 


\section{Fabrication and Assembly (cont)}

Internal Use Only

Discipline/Task

Mockup Testing

Mech. Engr. Support

Elec. Engr. Support

Instrument Tech.

Fitters

Machinist

Material Costs

Project Management and

Reactor Interface (8 months)

Project Manager

Tech Support

Admin Support
Labor Hours

(a) Hourly rate

$200 @ \$ 150 / \mathrm{hr}$ $200 @ \$ 150 / \mathrm{hr}$

120@\$75/hr

120@\$80/hr

200@\$80/hr

1000@\$150/hr

120@\$150/hr

120@\$80/hr
Material

Costs (\$K) Costs (\$K)

50.0

50.0

30.0

9.0

9.6

16.0

40.0

40.0

5.0

155.0

18.0

1.5

11.1

Subtotal

$1,823.3$

547.0

Contingency (30\%)

71.1

Safeguards \& Security (3\%)

73.2 


\section{Irradiation}

Internal Use Only

Discipline/Task

Irradiation Unit Charges

Does Not Include IU charges

Experiment Insertion into ATR (2 insertions)

Reactor Operators

Craft Support

Engr. Procedures

Engineer

Irradiation Support (12 months)

Training Prep. for Ops

Training for Ops

ATRC Plan, Ops, \& Data

Reactor Operators (1/4)

Experiment Engr. (1/4)

As-Run Analysis (both stages)

Thermal

Physics

Project Management

Project Manager (1/2)

Tech Support

Admin Support
Labor Hours

(a) Hourly rate
Material Total

Costs (\$K) Costs (\$K)
$40 @ \$ 80 / \mathrm{hr}$

80@\$80/hr

$120 @ \$ 150$

80@\$150/hr

80@\$90/hr

100@\$90/hr

200@\$140/hr

600@\$80/hr

600@\$150/hr

160@\$150/hr

600@\$170/hr

1600@\$150/hr

400@\$150/hr

400@\$80/hr
3.2

6.4

18.0

12.0

7.2

9.0

28.0

48.0

90.0

24.0

102.0

20.0

260.0

60.0

32.0

699.8

70.0

23.1

23.8 


\section{Handling and Packaging}

Internal Use Only

\section{Discipline/Task}

Canal Transfers (1transfer)

Rx Operators

Canal Operators

Equip. Operators

RadCon Support

Procedures

Engineer

Tooling

(Canal Transfer \& Disassy)

Machinist

Welders

Engineer
Labor Hours

(a) Hourly rate
Material

Costs (\$K) Costs (\$K)
$20 @ \$ 80 / \mathrm{hr}$

$30 @ \$ 80 / \mathrm{hr}$

40@\$80/hr

$20 @ \$ 80 / \mathrm{hr}$

120@\$150/hr

$20 @ \$ 150 / \mathrm{hr}$
1.6

2.4

3.2

1.6

18.0

3.0

150@\$80/hr

12.0

50@\$80/hr

75@\$150/hr

11.3

Canal Disassy Preparations for Shipment

Canal Operators

RadCon Support

Canal Procedures

Engr. Support

Canal Shipments

Canal Operators

Equipment Operators

RadCon Support

Rad Engr.

Shipper

Physics (ORIGEN)

Engr. Support

Cask \& Truck Rentals 90@\$80/hr

30@\$80/hr

60@\$150/hr

40@\$150/hr

40@\$80/hr

40@\$80/hr

40@\$80/hr

40@\$150/hr

40@\$150/hr

40@\$170/hr

40@\$150/hr

1 rental@\$84.0K each

900@\$150/hr

$100 @ \$ 150 / \mathrm{hr}$
7.2

2.4

$\begin{array}{ll}7.0 & 16.0\end{array}$

6.0

3.2

3.2

3.2

6.0

6.0

6.8

6.0

84.0

Project Management (6 months total)

Project Manager (1/2)

Tech Support

Subtotal

Contingency (15\%)

Safeguards \& Security (3\%)

DOE FAC (3\%) 